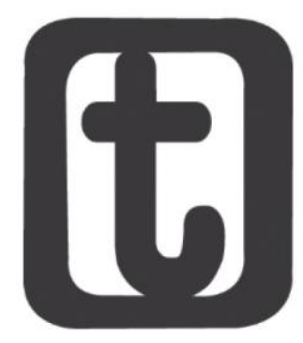

\title{
DIRETRIZES CURRICULARES E CULTURA: SOBRE FORMAÇÃO E PRÁTICA PROFISSIONAL
}

\author{
Curricular guidelines and culture: on the professional formation and practice \\ Paula Kropf* \\ https://orcid.org/0000-0001-6869-6612
}

\section{RESUMO}

Este artigo intenciona apresentar algumas reflexões introdutórias sobre o estudo da cultura e sua relação com a formação e a prática profissional do Serviço Social. Resgatamos pontos centrais das Diretrizes Curriculares, com particular ênfase no que tange ao conjunto de saberes a serem contemplados no processo formativo de assistentes sociais, localizando de que modo uma compreensão crítica do processo histórico pressupõe considerar a questão cultural. Foi proposto pensá-la a partir do que nomeou Raymond Williams como Materialismo Cultural, onde, enquanto prática social, é constituída e constituinte simultaneamente do modo de produção e reprodução da vida social. Ao final, tentamos elucidar algumas possibilidades centradas na prática profissional e em como a contemporaneidade requisita, com crescente complexidade, respostas que possuam qualificada apreensão da realidade.

\section{PALAVRAS-CHAVE}

Diretrizes Curriculares. Cultura. Serviço Social. Formação Profissional.

\section{ABSTRACT}

This paper aims to present some thought on the study of culture and its relationship with the Social Work formation and professional practice. We recover the central points of the Curriculum Guidelines, with particular emphasis on the knowledge set to be considered in the training process of social workers, locating how a historical process critical analysis presupposes considering the cultural issue. It was proposed to work with what Raymond Williams named as Cultural Materialism, where, as a social practice, it constituent and constituted simultaneously by the production and reproduction mode of social life. As conclusion, we try to elucidate some possibilities centered on professional practice and as a nowadays requirement, formulations which a in-depth understanding of reality.

\section{KEYWORDS}

Curriculum Guidelines. Culture. Social Work. Professional Formation.

\footnotetext{
* Assistente Social. Doutora em Serviço Social. Professora Adjunta da Escola de Serviço Social da Universidade Federal Fluminense. (UFF, Niterói, Brasil). Rua Miguel de Frias, 9, Niterói, Rio de Janeiro, CEP.: 24220-900. E-mail: paulakropf@gmail.com.
}

DOI 10.22422/temporalis.2020v2on40p64-76

○ A(s) Autora(s)/O(s) Autor(es). 2019 Acesso Aberto Esta obra está licenciada sob os termos da Licença Creative Commons Atribuição 4.0 Internacional (https://creativecommons.org/licenses/by/4.o/deed.pt_BR), que permite copiar e redistribuir o material em qualquer suporte ou formato, bem como adaptar, transformar e criar a partir deste material para qualquer fim, mesmo que comercial. O licenciante não pode revogar estes direitos desde que você respeite os termos da licença. (https://creativecommons.org/licenses/by/4.o/deed.pt_BR), que permite copiar e redistribuir o material em qualquer suporte ou formato, bem como adaptar, transformar e criar a partir deste material para qualquer fim, mesmo que comercial. O licenciante não pode revogar estes direitos desde que você respeite os termos da licença.

Temporalis, Brasília (DF), ano 20, n. 40, p. 64-76, jul./dez. 2020. | ISSN 2238-1856 


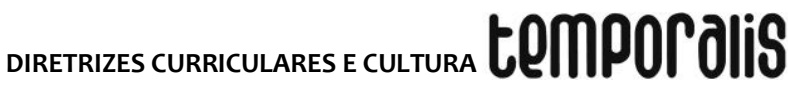

\section{INTRODUÇÃO}

$\mathrm{O}$

presente texto tenta colocar em contato alguns pontos que possibilitem contribuir para pavimentar a importância do estudo sobre a questão da cultura na formação profissional de assistentes sociais. É particularmente fruto das reflexões lapidadas pelas atividades do projeto de pesquisa desenvolvido enquanto docente no curso de Serviço Social, que coaduna acúmulos construídos ao longo da trajetória de formação acadêmica. Para isso, tentaremos primeiramente recuperar os elementos fundantes das Diretrizes Curriculares da ABEPSS, observados a partir de sua correspondência como um dos marcos na consolidação de um projeto ético-político profissional. Desta tomada, pensar a proposta que angula o processo formativo, entendendo a articulação de sua estruturação com o que se produziu de compreensão sobre a dimensão cultural na vida social.

Este movimento inicial é seguido então de uma aproximação com uma chave de leitura acerca da cultura que, ao posicioná-la como prática social, se inscreve na esteira do conhecimento produzido a partir da obra de Marx e da subsequente tradição marxista. Finalmente, tomando como exposto o entrelace entre as bases que alicerçam a formação profissional, expressas nas Diretrizes Curriculares para os cursos de Serviço Social, e o lugar da cultura na sociabilidade, passamos para um suposto ponto de chegada. Nele, amarramos o campo de possibilidade constituidoras do trabalho profissional, no que tange à sua relação com o conhecimento da totalidade da vida social e o quanto a realidade põe como demanda a exigência de elaboração de estratégias e respostas em crescente complexidade.

\section{AS DIRETRIZES CURRICULARES E A FORMAÇÃO PROFISSIONAL}

A formação profissional, tomada como um processo, é observada inscrita como parte da organização da vida social e suas relações, no âmbito de uma totalidade. Portanto, está em transformação, adquirindo contornos particulares que vão corresponder ao modo como a profissão vem se elaborando, respondendo ao movimento do real que ressoa em um chão histórico. Neste sentido, também é significativo que a empreitada de examinar com profundidade o processo formativo estabelece conexão com os caminhos que o Serviço Social brasileiro - e também latino-americano - percorre desde os desdobramentos da relação entre profissão e sociedade, e desembocam no Movimento de Reconceituação'.

\footnotetext{
1 Netto (2005) vai dizer que o Movimento de Reconceituação é impulsionado pela inquietação de assistentes sociais que se viram questionando "[...] o papel da profissão em face de expressões concretamente situadas da 'questão social', sobre a adequação dos procedimentos profissionais tradicionais em face das nossas realidades regionais e nacionais, sobre a eficácia das ações profissionais, sobre a pertinência de seus fundamentos pretensamente teóricos e sobre o relacionamento da profissão com os novos protagonistas que surgiam na cena político-social" (NETTO, 2005, p. 9).

Embora inicialmente tenha se constituído de uma "frente ampla" de profissionais e suas "[...] diferentes concepções de história, de sociedade e, naturalmente, das mudanças sociais em curso à época [...]" (NETTO, 2005, p. 10), o seu desenrolar se desenha pela formação de algumas correntes distintas de elaboração acerca das requisições e respostas postas pelo contexto sócio-histórico de outrora. Parte delas adotavam uma tentativa de incorporação das insígnias da modernização, defendendo uma adequação da profissão às exigências daquele tempo. Mas outro grupo tratou de elaborar uma crítica tanto às bases conservadoras da profissão quanto aos fatores que sustentavam a realidade social e o impulso desenvolvimentista. Deste
}

Temporalis, Brasília (DF), ano 20, n. 40, p. 64-76, jul./dez. 2020. | ISSN 2238-1856 
Cabe aqui retomarmos brevemente as condições históricas que, mundialmente, movimentavam erupções críticas em campos diversificados - cuja raiz se encontra nos limites intrínsecos à ordem capitalista. O encerramento das possibilidades expansivas do capital que vinham se desenvolvendo desde o fim da Segunda-Guerra mundial ocasionaram a ampliação de conflitos associados ao aprofundamento das manifestações da desigualdade elementar à lógica em curso. Com isso, o que se tem é a preparação de um terreno fértil para a efervescência das lutas sociais, organizadas a partir da "[...] mobilização das classes subalternas em defesa de seus interesses imediatos" (NETTO, 2005, p. 7). Se o cenário se apresentava em alcance mundial, no Brasil, as particularidades acenavam para uma promessa desenvolvimentista, empurrada pela ideia da necessidade de cumprir a etapa de modernização de suas forças produtivas, conservando a base das relações de dominação entre os países - centro e periferia. Para conter o avanço da mobilização social em curso, e garantir o livre fluxo dos interesses escusos ao movimento democrático, a instauração de um regime militar ditatorial dá o tom por duas décadas, sendo este o caldo que vai derramar sobre o Serviço Social sabores de difícil palatabilidade.

Sabemos que a aproximação com o marxismo, acompanhada do fortalecimento do vínculo com a universidade com subsequente expansão dos cursos de pós-graduação e, consequentemente, de uma produção teórica de fôlego, são alguns dos marcos timbrados por um direcionamento alinhado com a intenção de romper com 0 conservadorismo que imprime a tônica de constituição da profissão em sua origem. A refutação do tradicionalismo se pretendia de abrangência ampla, contemplando a intervenção profissional, a dimensão teórico-metodológica e, também, a formação. Todos estes aspectos estavam reunidos em torno do esforço em compreender a profissão localizada no processo sócio-histórico em curso. Segundo o documento da ABEPSS, o marco da redefinição do projeto profissional dos anos 80 foi o tratamento dispensado ao significado social da profissão, enquanto especialização do trabalho coletivo, inserido na divisão social e técnica do trabalho. (ABEPSS, 1996, p. 5) A busca pelo significado social da profissão, iniciada nos anos 80, vai alcançar hegemonia na década seguinte, consolidando a sua dimensão política e valores centrais a partir de parâmetros normativos expressos na Lei de Regulamentação da Profissão, no Código de Ética Profissional (CFESS, 1993) e nas Diretrizes Curriculares de 96. Tais conquistas se desenham em meio às transformações ocorridas nos anos 90, advindas com a reorientação do processo produtivo, impactando as relações sociais, o trabalho, e tornando absoluta a mercantilização; consequentemente, alterando também a esfera estatal.

Esses elementos guiam o processo de consolidação de um projeto profissional mais amplo, acentuando a ênfase na compreensão acerca da questão social, como fundamento constitutivo da profissionalização do Serviço Social. Esta premissa está articulada diretamente à dimensão da formação profissional, à medida que se reconhece a centralidade da mesma para a construção de conhecimento acerca da relação entre

último é que vai ganhar força, como já abordado em ampla bibliografia, o percurso crítico de localizar a profissão em novos planos, em organização enquanto categoria e no âmbito acadêmico. Deste trampolim é que, nos anos 80, presenciaríamos o fortalecimento da recusa ao tradicionalismo, sendo "[...] adequado caracterizar o desenvolvimento deste 'Serviço Social crítico' no Brasil como herdeiro do espírito da Reconceituação" (NETTO, 2005, p. 18). Não sendo o objetivo central do presente artigo se aprofundar sobre o Movimento de Reconceituação, indicamos para leitura sobre o tema a obra de José Paulo Netto, Ditadura e Serviço Social, publicada pela Editora Cortez.

Temporalis, Brasília (DF), ano 20, n. 40, p. 64-76, jul./dez. 2020. | ISSN 2238-1856 


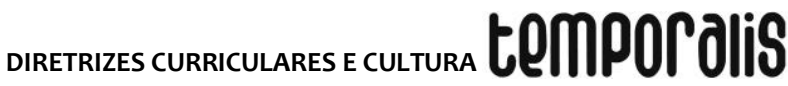

questão social e capitalismo, considerando as particularidades e desdobramentos desta lógica sistêmica no contexto brasileiro. Ademais, esta reflexão desagua no processo de trabalho do Serviço Social, especialmente em como historicamente a profissão vem respondendo à desigualdade fundante da sociabilidade capitalista.

As Diretrizes Curriculares então, ao pautarem uma base comum para orientar os cursos de graduação e seus respectivos currículos, o fazem alinhadas ao conjunto de valores que Ihe conferem legitimidade, aos objetivos e funções definidos, aos requisitos (teóricos, práticos e institucionais) para o seu exercício, "[...] bases das suas relações com os usuários de seus serviços, com as outras profissões e com as organizações e instituições sociais privadas e públicas (inclusive o Estado, a que cabe o reconhecimento jurídico dos estatutos profissionais). Em suma, à auto-imagem de uma profissão" (NETTO, 2006, p. 4).

Centrando na questão da formação, temos que há o estabelecimento de princípios norteadores da mesma. Destacamos, dos princípios que devem fundamentar a formação profissional, a dimensão investigativa como indissociável da intervenção, como elemento central da relação entre teoria e realidade; ancorada em um "rigoroso trato teórico, histórico e metodológico da realidade social, que possibilite a compreensão dos problemas e desejos com os quais o profissional se defronta no universo da produção; e reprodução da vida social". Assim, se busca uma formação capaz de permitir a compreensão da totalidade orientada pela "[...] adoção de uma teoria social crítica" (ABEPSS, 1996, p. 6). Os demais elementos possibilitam assegurar condições de desenvolvimento do processo formativo pautado pela sua qualificação e aprimoramento constantes no que tange à formulação de respostas profissionais frente às expressões da questão social. Além disso, amarradas por um lastro ético transversalizado e rigor no cumprimento da legislação profissional vigente.

Com a proposta de aproximar cada vez mais o processo de formação da realidade da vida social, um elemento central é a nova organização da lógica curricular, cujo pressuposto está centrado na afirmação de um conjunto de conhecimentos indissociáveis, dispostos em núcleos de fundamentação, a saber: 1- Núcleo de fundamentos teórico-metodológicos da vida social; 2-Núcleo de fundamentos da particularidade da formação sócio-histórica da sociedade brasileira; 3- Núcleo de fundamentos do trabalho profissional (ABEPSS, 1996).

O Núcleo de fundamentos teórico-metodológicos da vida social corresponde aos conhecimentos relativos à compreensão, sob a perspectiva de totalidade, do ser social, sendo este o responsável por oferecer a base fundamental para o aprofundamento em particularidades referentes à sociedade brasileira e ao trabalho profissional. Sendo assim, a construção de saberes tomando o ser social como elemento central, se realiza orientado pela dimensão da historicidade do processo social, entendendo o trabalho como raiz para a reprodução da vida social no capitalismo.

O Núcleo de fundamentos da particularidade da formação sócio-histórica da sociedade brasileira está relacionado ao conjunto de conhecimentos referentes aos aspectos que conformam a constituição da sociedade brasileira, considerando a totalidade das dimensões histórica, econômica, política e cultural. A chave de compreensão neste núcleo dialoga com o anterior, de modo que angula os esforços acima mencionados pelo pressuposto de que o Brasil ocupa determinada posição dentro da ordem capitalista, em

Temporalis, Brasília (DF), ano 20, n. 40, p. 64-76, jul./dez. 2020. | ISSN 2238-1856 
relação aos outros países. Este fato faz com que, ao longo dos séculos, tenhamos carregado traços não superados e que, em alguma medida, permanecem preenchidos de sentido. Além disso, são também abordados os conceitos de Estado e as diferentes constituições do mundo do trabalho.

Já o terceiro, o Núcleo de fundamentos do trabalho profissional, objetiva agregar os conhecimentos contemplados nos eixos anteriores em torno da constituição do campo da atuação profissional do serviço social, considerando de forma abrangente os conteúdos correspondentes. Assim, para tal, consiste em promover a compreensão acerca da profissionalização do Serviço Social - devidamente posicionada tendo como chão o processo histórico - e a necessidade, ao pautar a intervenção, do reconhecimento das múltiplas expressões da questão social. Tomar este ponto como pressuposto significa também observar que a elaboração e execução de respostas às demandas postas pela realidade nos espaços sócio ocupacionais, se fazem a partir da percepção acerca das dimensões constitutivas da prática profissional, norteadas pela mútua indissociabilidade, onde a "[...] 'forma de aparecer' da profissão [...]" (SANTOS; SOUZA FILHO; BACKX, 2012, p. 27), ou seja, sua face técnica-operativa, deve se apresentar contemplando a teóricometodológica e a ético-política. Implica aqui também a constatação de que, uma vez que a profissão possui um caráter eminentemente interventivo, a atuação tem como exigência ser pautada por uma capacidade de análise da realidade, construída através do acúmulo de conhecimentos possibilitado pelos conteúdos abordados nas atividades realizadas ao longo do processo formativo, orientadas pelos núcleos de fundamentação.

Quando falamos em indissociabilidade de conhecimentos e observamos os núcleos de fundamentação, é preciso que tenhamos em mente o reconhecimento sobre como tal significado se apresenta ou, como sua potencialidade pode ser ativada nos espaços em que o processo formativo acontece. Assim, evitando, portanto, a individualização e naturalização das manifestações da questão social, ou seja, de uma dinâmica que está enraizada nas bases da ordem social vigente. "Remete, pois, a um entendimento do Serviço Social que tem como solo a história da sociedade, visto ser daí que emanam as requisições profissionais, os condicionantes do seu trabalho e as respostas possíveis formuladas pelo assistente social" (ABEPSS, 1996, p. 13).

Neste sentido, a temática da cultura exerce lugar de relevância no processo de formação profissional em Serviço Social. Esta importância se manifesta por algumas direções, no que diz respeito mais estritamente à dimensão formativa, expressas nas Diretrizes Curriculares. Temos, como visto acima, que a proposta curricular está articulada à compreensão de que a efetivação de um projeto de formação profissional está orientada diretamente a um conjunto de conhecimentos indissociáveis. Estes, organizados em núcleos de fundamentação, indicam que pensar a totalidade histórica da vida social "[...] implica em reconhecer as dimensões culturais, ético-políticas e ideológicas dos processos sociais, em seu movimento contraditório e elementos de superação" (ABEPSS, 1996, p. 10)

Embora seja consensual a relevância do estudo da temática no Serviço Social, ainda assim é identificada a permanência da demanda por maior abrangência e aprofundamento de sua discussão. 


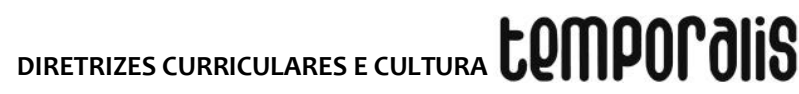

entre os quais merecem destaque: a relação indivíduo/sociedade; as relações entre as macroanálises e as microssituações enfrentadas no cotidiano profissional; as relações entre o universal, o particular e o singular; as relações entre objetividade e subjetividade; a questão da cultura, que, entre outras, merecem uma atenção especial, dada sua importância e incidência no fazer profissional (IAMAMOTO, 2010, p. 95).

Aprofundar os estudos sobre cultura com vistas a compreender a transversalidade com que atravessa a constituição das relações sociais e suas particularidades no capitalismo contemporâneo é reafirmar o comprometimento em garantir que formação e prática profissional estejam assentadas no esforço em desvelar as manifestações aparentes e incursionar pela radicalidade que constitui o chão de nossa sociabilidade. Alimentando a busca por respostas profissionais que, sintonizada com o Projeto Ético-político, tenha como motor a negação desta forma social e a permanente defesa da transformação.

\title{
PRISMAS SOBRE CULTURA
}

\begin{abstract}
5. O TRABALHO DA PROFESSORA NO MÉTODO PAULO FREIRE
(A atriz que representa a Professora entra com um vaso de flores e uma lousa. Senta-se de costas para o público, de frente para um grupo de camponeses que está de pé. Vira-se para falar diretamente aos espectadores.)

PROFESSORA - Eu sou uma professora, devo alfabetizar homens adultos. Mas antes de ensinar o alfabeto, quero que entendam que são sujeitos, que estão no mundo e com o mundo, aprendendo com ele e transformando-o com seu trabalho. Quando do barro fazem um vaso, transformam a natureza, e quando têm a necessidade de enfeitá-lo com flores continuam a transformá-la, produzindo cultura. Por isso, o vaso, as flores, as letras têm de ser de todos. $\left(\right.$ CARVALHO, 2014, p. 29-30) ${ }^{2}$
\end{abstract}

Deste caminho, de um modo geral, permanece e se acentua a insistente ideia de que é procedente uma inquietação acerca da urgência em aprofundar uma crítica da cultura nos tempos atuais, confrontando um marco conceitual relativo ao tema que outrora coincidiu com a realidade, mas que hoje parece desencaixado. Entender esse desajuste é fundamental, considerando: 1- a necessidade de posicionar a dimensão cultural no que tange à vida social, ao que somos; 2 - o esforço de compreender as implicações e os desdobramentos do avanço de um capitalismo maduro, que são a chave para alcançar este descompasso entre o que poderíamos ser - e não somos - e o que efetivamente nos constitui.

Uma chave de interpretação interessante sobre o conceito de cultura pode ser elaborada recuperando a contribuição do materialismo cultural de Raymond Williams. Para o autor, cultura é processo e, enquanto tal, parte das relações de produção e reprodução da vida social. Uma de suas ideias centrais, e com a qual trabalhamos no presente artigo, reside na transformabilidade das palavras em seus significados, acompanhando o próprio desenrolar da história; com isso, o termo cultura, que é o nosso interesse, se designava para expressar a noção de cultivo, da natureza e do homem.

\footnotetext{
${ }^{2}$ Trecho do espetáculo Ópera dos vivos, escrito e encenado pela Companhia do Latão. Estreia em 2010, no CCBB, Rio de Janeiro. A companhia lançou uma publicação do texto da peça pela editora Outras Expressões, em 2014.
}

Temporalis, Brasília (DF), ano 20, n. 40, p. 64-76, jul./dez. 2020. | ISSN 2238-1856 
Elucidações em torno do conceito de cultura apresentam conclusões distintas, orientadas tanto pela perspectiva com que se lê a realidade, quanto pelos campos de saberes que as oferecem sustentação. Além disso, o movimento constante do processo histórico oferece um colocar de questões sob definições em transformação. Tal busca por significados é uma inquietação sempre atual, pois reflete o interesse em compreender como, através dos tempos, os seres humanos vêm organizando e produzindo as suas relações e vida em sociedade; como estão inseridos no mundo e o transformam.

Dado que vivemos a realidade, e esta tal como se apresenta, embora mantenha conexão com heranças que por vezes ainda vigoram, já não é mais a de outrora, que ficara como parte componente do percurso histórico. Assim, é importante considerar a relevância - e urgência - de empreender uma compreensão acerca de um tempo e, além disso, considerando as experiências e contribuições anteriores a partir de como podem nos ajudar a compreender a atualidade.

Maria Elisa Cevasco (2003), em Dez lições sobre estudos culturais, faz uma breve síntese dos sentidos da palavra cultura ao longo dos anos. Informa que a sua origem está no latim colere, cujo significado englobava o habitar e adorar. Para a autora, estes sentidos hoje permanecem como, no primeiro - 'habitar', sendo referentes à colono e colônia, e o último - 'adorar', relacionado ao culto, cultuar, 'honrar com veneração' (WILLIAMS, 2007, p. 117). O sentido de cultivo se estendeu ao âmbito das aptidões mentais e espirituais e, junto das variáveis acima, alcançavam a preponderância no século XVI. Durante esse período, cultura era uma atividade. O uso da palavra relacionada à 'civilização' começa a partir do século XVIII e, "[...] tomada como um substantivo abstrato, para designar um processo geral de progresso intelectual e espiritual tanto na esfera pessoal como na social." (CEVASCO, 2003, p. 9)

Para Cevasco (2003), cultura e civilização são palavras que além de carregarem o sentido descritivo, também levam consigo uma perspectiva normativa, do que deveria ser. Isso se fortaleceu com as transformações advindas na sociedade inglesa a partir da Revolução Industrial. A autora se refere a isso como uma importante virada de sentido. Indo além, o termo passou a carregar consigo também uma crítica, como reação ao processo de transformação em curso. Deixa de conter o desenvolvimento das faculdades mentais e, durante o século XX, toma como tônica principal as artes, estas como "[...] as obras e práticas que representam e dão sustentação ao processo geral de desenvolvimento humano" (CEVASCO, 2003, p. 10).

Esta rápida apresentação sobre o sentido de cultura ao longo da história se conecta com - lugar escolhido para principiar uma observação sobre o pensamento de Raymond Williams. Um bom ponto inicial para desbravar o mar teórico deste autor seria começar aportando em dois lugares. O primeiro deles seria em um trecho introdutório do livro Cultura e sociedade (WILLIAMS, 1969), onde o autor fala diretamente sobre a construção dos significados de cultura ao longo do processo histórico e termina por sintetizar a sua própria compreensão.

Os usos do termo cultura, dentre outros, foi uma das peças chaves da construção de seu pensamento. $\mathrm{O}$ autor inglês discute o conceito a partir do pressuposto de que este vem sofrendo alterações de significado à medida que acompanha as transformações e contextos históricos. Williams (1979) diz que, inicialmente, o termo cultura era designado para expressar a ideia de cultivo, da natureza e do homem. "'Cultura', antes dessas 


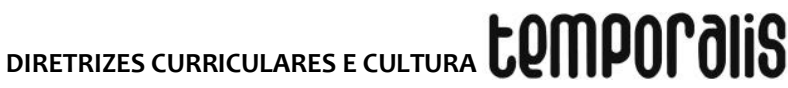

transições, era o crescimento e cuidado de colheitas e animais, e, por extensão, o crescimento e cuidado das faculdades humanas" (WILLIAMS, 1979, p. 18). Entretanto, com o advento da sociedade moderna, destaca o fato de que algumas palavras passam por uma ressignificação de seus sentidos anteriores, dentre elas, a cultura. Além disso, indica que o significado do termo está estritamente relacionado, assim como as suas decorrentes mudanças em consonância com o movimento histórico, ao de outras duas palavras: sociedade e economia.

A reconfiguração de seu significado tece correspondência às alterações no modo de vida e pensamento, acompanhando o fluxo das transformações ocorridas na forma de organização das relações sociais. Nesse sentido, para Williams (1969), a palavra cultura:

\begin{abstract}
Anteriormente significara, primordialmente, 'tendência de crescimento natural' e, depois, por analogia, um processo de treinamento humano. Mas este último emprego, que implicava, habitualmente, cultura de alguma coisa, alterou-se, no século dezenove, no sentido de cultura como tal, bastante por si mesma. Veio a significar, de começo, 'um estado geral ou disposição de espírito', em relação estreita com a ideia de perfeição humana. Depois, passou a corresponder a 'estado geral de desenvolvimento intelectual no conjunto da sociedade'. Mais tarde, correspondeu a 'corpo geral das artes'. Mais tarde ainda, ao final do século, veio a indicar 'todo um sistema de vida, no seu aspecto material, intelectual e espiritual (WILLIAMS, 1969, p. 18).
\end{abstract}

Aqui, em linhas mais diretas, vai desenhar um pouco de como funciona o seu movimento de pensamento, desde o modo como encontrava sentido para o termo ao observar a sua própria experiência, até a forma com que a trazia para ilustrar seu caminho teórico. Mais do que reforçar os sentidos de modo de vida, cultivo, hábitos e práticas desenvolvidas em torno de linguagens artísticas, quer demarcar o seguinte posicionamento, expresso textualmente: cultura é ordinária. No sentido da asserção de Williams, a cultura é habitual, é referente aos valores e práticas constituídos como costume por um determinado povo.

A palavra cultura era utilizada então para falar sobre dois sentidos: o primeiro correspondia ao modo de vida, os significados comuns; o outro, para significar as artes e o aprendizado, no sentido dos esforços criativos. Ao tomar a cultura como ordinária, centrava sua defesa no fato de que um de seus elementos fundantes era ser comum a todos. Os dois sentidos estariam intrinsecamente relacionados, dado que uma obra de arte carrega em si um modo de vida e experiência de um tempo determinado, e se relaciona com ele também produzindo novos significados. Uma definição não exclui a outra, portanto; em vez disso, se completam.

É a partir desta compreensão de cultura que, anos mais tarde, Williams vai elaborar a formulação denominada como Materialismo cultural que, em suas palavras:

O que eu diria ter conseguido formular, mas necessariamente por esta via, é uma teoria da cultura como um processo produtivo (material e social) e das práticas específicas, as 'artes', como usos sociais de meios materiais de produção (da linguagem como consciência prática às tecnologias específicas da escrita e de formas da escrita, passando pelos sistemas eletrônicos e mecânicos de comunicação) (WILLIAMS, 1976, p. 88, tradução nossa) ${ }^{3}$.

\footnotetext{
3 “[...] is a theory of culture as a (social and material) productive process and of specific practices, of 'arts', as social uses of material means of production (from language as material 'practical consciousness' to the
} 
Nela, está enfatizado o principal movimento de sua proposta: alçar a cultura a um lugar não mais dependente da esfera da produção, e sim parte dela. Rompendo, assim, com uma leitura de sociedade que dispunha de uma análise de suas partes fragmentadas, onde os valores, significados e linguagens estivessem subscritos em uma condição de dependência.

A conquista principal da elaboração teórica de Williams, acerca do materialismo cultural, é demarcar o lugar da cultura como parte indissociável do todo e, assim sendo, está interligada ao momento da produção material da vida. Neste sentido, Cevasco (2003) vai afirmar, com ênfase, que:

\begin{abstract}
A diferença fundamental que a contribuição de Williams traz ao debate é a percepção materialista de cultura: os bens culturais são resultado de meios também eles materiais de produção (indo desde a linguagem como consciência prática aos meios eletrônicos de comunicação), que concretizam relações sociais complexas envolvendo instituições, convenções e formas. Definir cultura é pronunciar-se sobre o significado de um modo de vida (CEVASCO, 2003, p. 23).
\end{abstract}

Raymond Williams enxergava sentido na cultura sob algumas angulações fundamentais. O primeiro: reivindicar um lugar da cultura como comum, ordinária, de todos. Aqui, sua oposição a uma 'cultura de minoria' não estava pautada somente por uma intenção de ruptura com um projeto elitista e agravador de desigualdades. Era também, e sobretudo, uma constatação inerente à definição de cultura que adotou. Se cultura é modo de vida e não só, mas pegando um de seus significados radicais, isto é algo que perpassa a totalidade da experiência humana. Todos os indivíduos produzem e são produzidos, estão imersos neste crivo - modo de vida. Afinal, estão vivos, se comunicam, utilizam linguagens como elemento de construção das interações; estabelecem relações sociais. Outra revisão de lugar, operada por Williams, retira a cultura da classificação mais usual de objeto e a reposiciona na condição de processo.

Com esses movimentos, essenciais, de afirmar a cultura como ordinária, e reativar as suas potências, para além da dependência de uma base material determinante, inaugura uma percepção que a assume como produzida e produtora de uma formação social. Se é produto e produz, se está intrinsecamente permeada na e pelas relações de produção, se contém em si e está contida substantivamente de uma dimensão material, então, a cultura deve ser tomada como prática social.

Partindo desta chave de compreensão da dimensão cultural, observá-la exige um esforço de construção de leitura da realidade contemporânea. Assim, então, requer trazer à tona as peças que constituem o modo de produção dos indivíduos em sociedade. Neste sentido, a elaboração de tal feito toma por base a análise de marxiana acerca do capitalismo, expressa em sua obra, entendendo a sua lógica como definidora da forma social vigente. A raiz fundamental está ancorada na centralidade do trabalho, tomando como pressuposto as particularidades que denotam o modo dos indivíduos produzirem coletivamente a vida.

specific technologies of writing and forms of writing, through to mechanical and electronic communications systems)." 


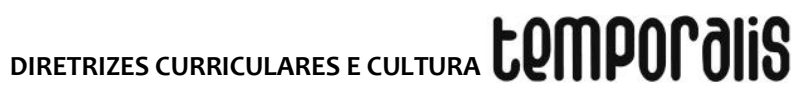

\section{PONTUANDO CONCLUSÕES: ALGUMAS CONSIDERAÇÕES SOBRE A PRÁTICA PROFISSIONAL E CULTURA}

O percurso até aqui tentou tecer um panorama acerca de como o estudo sobre cultura ocupa lugar de relevância no bojo dos elementos centrais das Diretrizes Curriculares da ABEPSS e, consequentemente, na formação profissional. É necessário, entretanto, evidenciar a opção de chave de leitura sobre cultura. Esta, sustentada pela contribuição de Raymond Williams, é construída a partir de uma perspectiva de prática social, simultaneamente produzida e produtora da realidade. Entende-se que o emaranhado de significados, valores, sentidos, o conjunto de traços que nos dizem sobre o cultivo do que é humano, devem possibilitar, no percurso do processo formativo, o fortalecimento dos esforços de compreensão da vida social em sua totalidade.

Parece incontestável quão essencial é para o exercício profissional que esteja abastecido por uma fundamentação teórica crítico-analítica, o que pode ser facilmente reafirmado se observada a trajetória histórica da profissão no Brasil, demarcando especialmente a virada advinda com o movimento de Reconceituação. Neste sentido, soa procedente esboçar alguns apontamentos mais aproximados entre o espaço da prática profissional e possíveis paralelos com a discussão sobre cultura.

As Diretrizes Curriculares vão afirmar que "A ação profissional, assim compreendida, exige considerar as condições e relações sociais historicamente estabelecidas [...]" (ABEPSS, 1996, p. 12), e daí extraímos duas questões centrais para a reflexão que este texto tenta operar. A primeira é: qual é a forma de compreensão da ação profissional que requisita ter em conta a assimilação de um amplo e consistente conhecimento sobre as condições e relações sociais historicamente estabelecidas? E, um outro ponto seria como são construídas estratégias de atuação frente aos desafios que despontam no movimento do real, dotados de crescente complexidade. Em que pese que a premissa por tomar como base de que forma historicamente se estabelecem as relações sociais, implica fundamentalmente nos contornos que desenham as respostas profissionais, à medida que exerce influência sobre o estado como ocorre o trânsito entre a manifestação e a recepção das demandas.

Neste sentido, as perguntas acima estão conectadas e sugerem um prumo essencial para o desbravar sobre a profissão em termos amplos. Em princípio, é preciso repetir que o Serviço Social está inscrito, é parte, da sociedade em curso e, como tal, se construiu e se constrói continuamente durante o desenvolvimento de sua trajetória histórica, sempre em aprimoramento - diante das ondulações promovidas pelo conjunto de elementos que compõe uma realidade em constante transformação. Por essa razão, não perder de vista a direção sobre a existência - fruto de intensa ebulição e organização da categoria consolidada de um projeto profissional e vislumbrar com nitidez o seu sentido é circunstância fundamental. Essa razão de ser, ou seja, os valores que conferem legitimidade à profissão em âmbito social - dentre suas outras dimensões - explicitados em caráter normativo, mas sem nele se esgotar, demarcam com nitidez uma escolha circunscrita em diversos campos. Esta se pauta radicalmente no entendimento da liberdade como um valor central, em que esteja garantida a possibilidade de existência de indivíduos sociais emancipados. Se infere então que, posto como horizonte, demonstra que há também uma atitude crítica para com a dinâmica social do capitalismo, cujo modo de funcionamento está indissociado da desigualdade, tendo a questão social como

Temporalis, Brasília (DF), ano 20, n. 40, p. 64-76, jul./dez. 2020. | ISSN 2238-1856 
decorrência. Assim, o Serviço Social faz a opção em seu projeto profissional pelo reconhecimento da necessidade de negação da lógica atual e construção de relações sociais erigidas em novas bases. E, é ao afirmar este lugar que fica evidente que, angulado pelos elementos éticos, o projeto profissional extrapola normativas e prescrições formais; segundo Netto (2006), faz supor que "[...] as opções teóricas, ideológicas e políticas dos profissionais - por isto mesmo, a contemporânea designação de projetos profissionais como ético-políticos revela toda a sua razão de ser: uma indicação ética só adquire efetividade histórico-concreta quando se combina com uma direção políticoprofissional" (NETTO, 2006, p. 8).

Portanto, o Serviço Social, em sua atuação, deve se construir cotidianamente a partir de um exercício de permanente presença da postura investigativa, direcionando as escolhas profissionais para a refutação da reprodução de práticas que corroborem com a manutenção de influências de suas bases tradicionais - a herança do conservadorismo, pragmática, desistoricizada. Estas, por sua vez contribuindo para o reforço de perspectivas de observação e intervenção que perpetuem a individualização e a naturalização das condições de vida socialmente colocadas.

Clamar pela historicidade do real vai além e nos implica em manter como guia a constatação de que o compromisso com os valores da profissão e a sua função social nos requisita atividade intelectual contínua. Conduzida pela constatação de que as contribuições de períodos anteriores, ainda que decisivas, nos mostram que "o mundo visto através daqueles olhos não é o nosso, embora com ele se pareça”. E, portanto, o conjunto de significados que nos chega às mãos pela tradição são imprescindíveis, "[...] mas nem todos conservam o seu sentido quando os aplicamos, como é preciso fazer, à experiência imediata" (WILLIAMS, 1969, p. 306). A recepção da relevância de um arcabouço teórico consolidado, e a procura por novas formas - em atitude crítica, deve acompanhar a busca motora pela atuação direta nas expressões que se fundam oriundas da desigualdade social.

O caráter interventivo da profissão se apresenta a partir da elaboração de respostas que contemplem as "[...] particularidades sócio-institucionais para a elaboração criativa de estratégias [...]" (ABEPSS, 1996, p. 13), que presumem formas de pensar pautadas por competência crítica de análise da realidade. Nessa medida, investigar é ponte para o fluxo entre a organização dos saberes adquiridos e sua aplicação no exercício profissional, de modo que os esforços sejam simultaneamente alimentados.

\footnotetext{
As estratégias e técnicas de operacionalização devem estar articuladas aos referenciais teórico-críticos, buscando trabalhar situações da realidade como fundamentos da intervenção. [...] As estratégias são, pois, mediações complexas que implicam articulações entre as trajetórias pessoais, os ciclos de vida, as condições sociais dos sujeitos envolvidos para fortalecê-los e contribuir para a solução de seus problemas/questões (ABEPSS, 1996, p. 14).
}

Cultura como prática social potencializa a compreensão sobre os pilares que sustentam esta sociabilidade e consequentemente confere qualificação na interpretação da realidade operada pela profissão, incidindo diretamente na elaboração criativa de alternativas para o enfrentamento das expressões da questão social. Fica como desafio aprofundar uma crítica à cultura em tempos que dissolvemos os laços com os traços de humanidade que nos constituiu. Recuperar o fio é repertório para a lista de músicas tocadas pelos violinistas do navio, enquanto ele afunda. 
Cultura como prática também nos desafia a pensar a reorganização dos significados simbólicos em que se assentam as relações sociais em que vivenciamos a materialidade do cotidiano. Importa recuperar que o desvelamento acerca do lugar da cultura quando pensamos a função pedagógica da profissão e seu caráter socioeducativo é outro caminho essencial para avançarmos em direção a uma superação dos desafios postos pela imediaticidade, na construção de espaços de troca, em que está colocada a possibilidade de atuação sobre a "[...] maneira de pensar e agir dos sujeitos envolvidos nos processos da prática” (ABREU, 2002, p. 17).

Colocar os tempos atuais na roupagem da cultura como outrora fora, certamente nos demandará ajustes, para que porventura lhe caiba mais adequadamente. Contudo, o processo histórico vem nos mostrando que para as nossas ações continuarem orientadas pelo sentido de nosso projeto profissional, é urgente a confecção de vestes radicalmente novas. Pois, sendo a cultura "[...] uma dimensão essencial na conformação da sociabilidade [...]" (IAMAMOTO, 2010, p. 400), também ela deve fazer parte do necessário esforço coletivo pelo descortinamento das tramas emaranhadas na realidade social.

\section{REFERÊNCIAS}

ABREU, Marina Maciel. Serviço Social e a organização da cultura: perfis pedagógicos da prática profissional. São Paulo: Cortez, 2002.

ABEPSS. Diretrizes gerais para o curso de Serviço Social. Rio de Janeiro: ABEPSS, 1996. Disponível em:

http://www.abepss.org.br/arquivos/textos/documento_201603311138166377210.pdf. Acesso em: 26 dez. 2020.

CARVALHO, Sérgio de. Ópera dos vivos: estudo teatral em quatro atos da Companhia do Latão. São Paulo: Outras Expressões, 2014.

CEVASCO, M. E. Dez lições sobre Estudos Culturais. São Paulo: Boitempo Editorial, 2003.

CFESS. Código de ética profissional do assistente social. 9. ed. Brasília (DF), 1993.

Disponível em: http://www.cfess.org.br/arquivos/CEP2011_CFESS.pdf. Acesso em: 26 dez. 2020.

IAMAMOTO, M. V. O debate contemporâneo do Serviço Social e a ética profissional. In: BONETTI, Dilsea A. et. al (org.). Serviço Social e ética: convite a uma nova práxis. São Paulo: Cortez, 2010.

IAMAMOTO, M. V. Serviço Social em tempo de capital fetiche: capital financeiro, trabalho e questão social. São Paulo: Cortez, 2010.

NETTO, J. P. A construção do projeto ético-político do Serviço Social. In: MOTA, Ana Elisabete; BRAVO, Maria Inês Souza; UCHÔA, Roberta et al. (orgs.). Serviço social e saúde: formação e trabalho profissional. São Paulo: Cortez, 2006. 


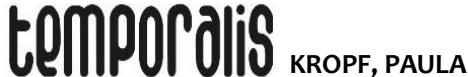

NETTO, J. P. O Movimento de Reconceituação 40 anos depois. Serviço Social e

Sociedade, São Paulo, ano 26, n. 84, nov. 2005.

SANTOS, Cláudia Mônica dos; SOUZA FILHO, Rodrigo de; BACKX, Sheila. A dimensão técnico-operativa do Serviço Social: Questões para Reflexão. In: SANTOS, Cláudia Mônica dos; BACKX, Sheila; GUERRA, Yolanda (org.). A Dimensão Técnico-operativa no Serviço Social: desafios contemporâneos. Juiz de Fora: UFJF, 2012. p. 15-39.

WILLIAMS, Raymond. Cultura e sociedade: 1780 - 1950. São Paulo: Comp. Ed. Nacional, 1969.

WILLIAMS, Raymond. Marxismo e literatura. Rio de Janeiro: Zahar, 1979.

WILLIAMS, Raymond. Notes on British Marxism since 1945. In: New Left Review NLR I/100, November-December 1976, pp. 81-94.

WILLIAMS, Raymond. Palavras-chave. São Paulo: Boitempo, 2007.

\section{PAULA KROPF}

Doutora pelo Programa de Pós-Graduação em Serviço Social da Escola de Serviço Social da Universidade Federal do Rio de Janeiro (PPGSS/ESS/UFRJ). Possui graduação em Serviço Social pela Universidade Federal do Rio de Janeiro (2006) e mestrado em Serviço Social pela Universidade Federal do Rio de Janeiro (2011). Atualmente é Professora Adjunta da Escola de Serviço Social da Universidade Federal Fluminense (UFF Niterói). 